This item was submitted to Loughborough's Research Repository by the author.

Items in Figshare are protected by copyright, with all rights reserved, unless otherwise indicated.

Modelling of $\mathrm{Nb}$ influence on phase transformation behaviours from austenite to ferrite in low carbon steels

PLEASE CITE THE PUBLISHED VERSION

http://dx.doi.org/10.1088/0965-0393/24/3/035016

PUBLISHER

(C) IOP

VERSION

AM (Accepted Manuscript)

LICENCE

CC BY-NC-ND 4.0

REPOSITORY RECORD

Wang, Li, Sally V. Parker, Andrew J. Rose, G.D. West, and Rachel Thomson. 2016. "Modelling of Nb Influence on Phase Transformation Behaviours from Austenite to Ferrite in Low Carbon Steels". figshare. https://hdl.handle.net/2134/22106. 


\title{
Modelling of Nb influence on phase transformation behaviours from austenite to ferrite in low carbon steels
}

\author{
L. Wang $^{1^{*}}$, S.V.Parker ${ }^{2}$, A.J.Rose ${ }^{2}$, G.D.West ${ }^{1^{* *}}$, R.C.Thomson ${ }^{1}$ \\ 1. Department of Materials, Loughborough University, Loughborough, LE11 3TU, UK \\ 2. Materials Design Department, Tata Steel R\&D, Swinden Technology Centre, Rotherham, S60 3AR, UK
}

\begin{abstract}
:
In this paper, a new model has been developed to predict the phase transformation behaviours from austenite to ferrite in Nb-containing low carbon steels. The new model is based on some previous work and incorporates the effects of $\mathrm{Nb}$ on phase transformation behaviours, in order to make it applicable for Nb-containing steels. Dissolved $\mathrm{Nb}$ atoms segregated at prior austenite grain boundaries increase the critical energy for ferrite nucleation, and thus the ferrite nucleation rate is decreased. Dissolved $\mathrm{Nb}$ atoms also apply a solute drag effect to the moving transformation interface, and the ferrite grain growth rate is also decreased. The overall transformation kinetics is then calculated according to the classic Johnson-MehlAvrami-Kolmogorov (JMAK) theory. The new model predictions are quite consistent with experimental results for various steels during isothermal transformations or continuous cooling.
\end{abstract}

Key words: niobium; transformation kinetics; nucleation rate; solute drag effect; low carbon steels

\section{Introduction}

Niobium is widely used as a micro-alloying element in steels as it can refine the grain size, which is beneficial for both strength and toughness, and provide precipitation

\footnotetext{
*L. Wang Now moves to Jaguar Land Rover UK, Mobile: +44 (0) 7859255713. Email address: liwangmaterials@outlook.com.

** G.D. West now moves to University of Warwick
} 
strengthening [1]. It has also been shown that $\mathrm{Nb}$ has a retardation effect on the transformation kinetics from austenite to ferrite, which is the most important phase transformation in many steel products [1-6]. It is quite beneficial for industry to utilise a metallurgical model to predict the transformation behaviour of $\mathrm{Nb}$ containing steels so that the heat treatment parameters can be optimised to increase the mechanical properties and reduce the cost with the minimum number of experimental trials [7]. It has been found that dissolved $\mathrm{Nb}$ atoms can delay both the nucleation rate and the grain growth rate during the transformation from austenite to ferrite [2]. There are currently many existing models for phase transformation kinetics predictions [4-10]. A metallurgical model which is developed by Parker and Bhadeshia [7-8], is one of the most complete phase transformation models for steels. From the model, the phase transformation kinetics is calculated step by step according to the temperature change or time increment, and at each step, the fraction of each phase is calculated. However, the effect of $\mathrm{Nb}$ is not considered in the model. In order to incorporate the effects of $\mathrm{Nb}$ on phase transformation kinetics from austenite to ferrite, the effect on both ferrite nucleation and grain growth should be considered. It is believed that dissolved $\mathrm{Nb}$ atoms in austenite can apply a solute drag effect during the transformation [2-4,6,11-14]. Although the solute drag effect caused by $\mathrm{Mn}$ has been studied for many years [15-19], the $\mathrm{Nb}$ induced solute drag effect still requires an accurate understanding and quantification.

In the present paper, the effect of $\mathrm{Nb}$ on ferrite nucleation rate is quantified. The effect of $\mathrm{Nb}$ on ferrite grain growth rate is also discussed and quantified, and a $\mathrm{Nb}$ factor is incorporated to describe the delay effect of $\mathrm{Nb}$ on grain growth. A new model is developed by incorporating the effects of $\mathrm{Nb}$ on ferrite nucleation rate and grain growth rate into the Parker and Bhadeshia's model, and the classic JMAK theory [20-22] is used to calculate the overall transformation kinetics. Dilatometer results of isothermal transformation and continuous cooling for different steels are utilised to verify the applicability of the new model. 


\section{Experimental procedure}

Four laboratory cast low carbon steels with the same base chemistry but different niobium contents were provided by Tata Steel, and their chemical compositions are listed in Table 1. Samples were cut into cylindrical shape with a length of $10 \mathrm{~mm}$ and a diameter of $5 \mathrm{~mm}$ for dilatometer testing. A dilatometer (DIL 805A/D) was utilised for heat treatments and recording transformation kinetics. ThermoCalc in conjunction with the TCFE v6 database was utilised for thermodynamic calculations, and to determine heat treatment temperatures. Heat treatment temperature profiles are shown in Figure 1 (a) and (b) for isothermal transformation and continuous cooling, respectively. Samples were heated to $1250^{\circ} \mathrm{C}$ for austenitisation and dissolution of pre-existing niobium precipitates and held at that temperature for different times to obtain an average prior austenite grain size of $\sim 80 \mu \mathrm{m}$ in steels 1-3 [4]. Austenitisation times were 5 seconds for Steel 1, 1 minute for Steel 2 and 5 minutes for Steel 3. Steel 4 was from a different batch of casts to Steels 1-3. It was not directly compared with Steels 1-3 for the transformation kinetics, but used as test samples with a different prior austenite grain size to validate the model. Steel 4 was held at $1250^{\circ} \mathrm{C}$ for 5 minutes resulting in an average prior austenite grain size of $\sim 60 \mu \mathrm{m}$.

After austenitisation at $1250^{\circ} \mathrm{C}$, some samples were then fast cooled to isothermal transformation temperatures of $750^{\circ} \mathrm{C}, 725^{\circ} \mathrm{C}, 700^{\circ} \mathrm{C}, 675^{\circ} \mathrm{C}$ and $650^{\circ} \mathrm{C}$, and held for 15 minutes, before being quenched to room temperature. Additional samples were fast cooled to $900^{\circ} \mathrm{C}$ from $1250^{\circ} \mathrm{C}$, to avoid precipitation of any $\mathrm{Nb}$ in the austenite before transformation, and then continuously cooled to room temperature at a constant cooling rate from $0.1^{\circ} \mathrm{C} / \mathrm{s}$ to $100^{\circ} \mathrm{C} / \mathrm{s}$. The dilatometer data and final microstructures were analysed to obtain the fraction transformed versus temperature or time curves. Full details of the dilatometry results and microstructural analysis were described in a previous paper [4].

Table 1: Chemical compositions of steels (wt. \%)

\begin{tabular}{cccccccc}
\hline Steel & $\mathrm{C}$ & $\mathrm{Nb}$ & $\mathrm{N}$ & $\mathrm{Si}$ & $\mathrm{Mn}$ & $\mathrm{Al}$ & $\mathrm{Fe}$ \\
\hline 1 & 0.110 & $<0.001$ & 0.006 & 0.23 & 0.99 & 0.034 & $\mathrm{Bal}$ \\
2 & 0.105 & 0.009 & 0.006 & 0.23 & 1.00 & 0.030 & $\mathrm{Bal}$ \\
3 & 0.105 & 0.028 & 0.006 & 0.23 & 0.99 & 0.031 & $\mathrm{Bal}$ \\
4 & 0.096 & 0.045 & 0.005 & 0.23 & 1.01 & 0.029 & $\mathrm{Bal}$ \\
\hline
\end{tabular}


Austenitisation $1250^{\circ} \mathrm{C}, 5 \mathrm{~s}$ to 5 minutes

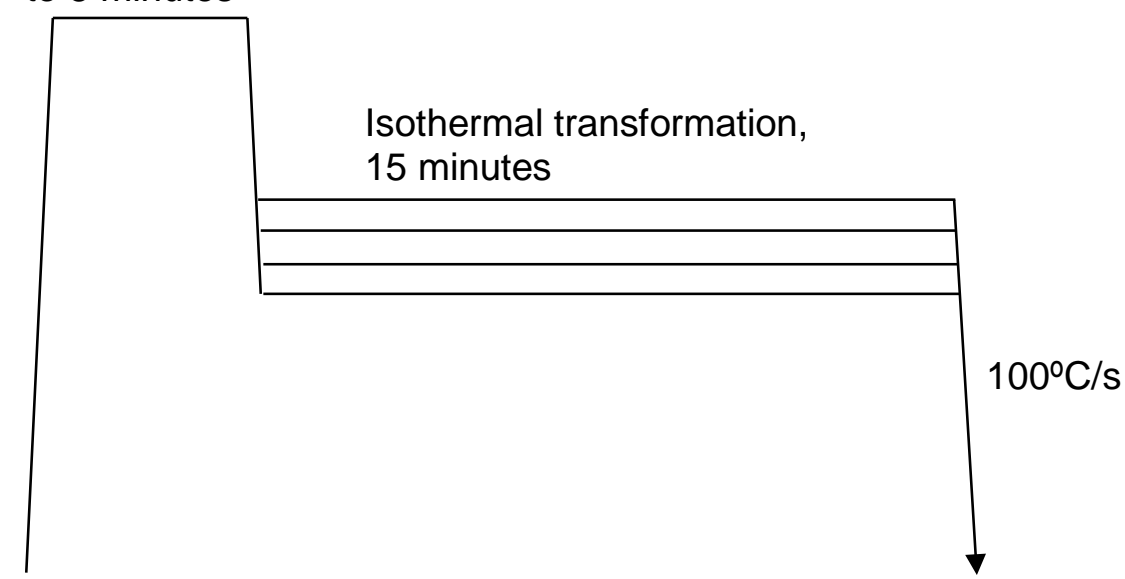

(a)

Austenitisation $1250^{\circ} \mathrm{C}, 5 \mathrm{~s}$ to 5 minutes

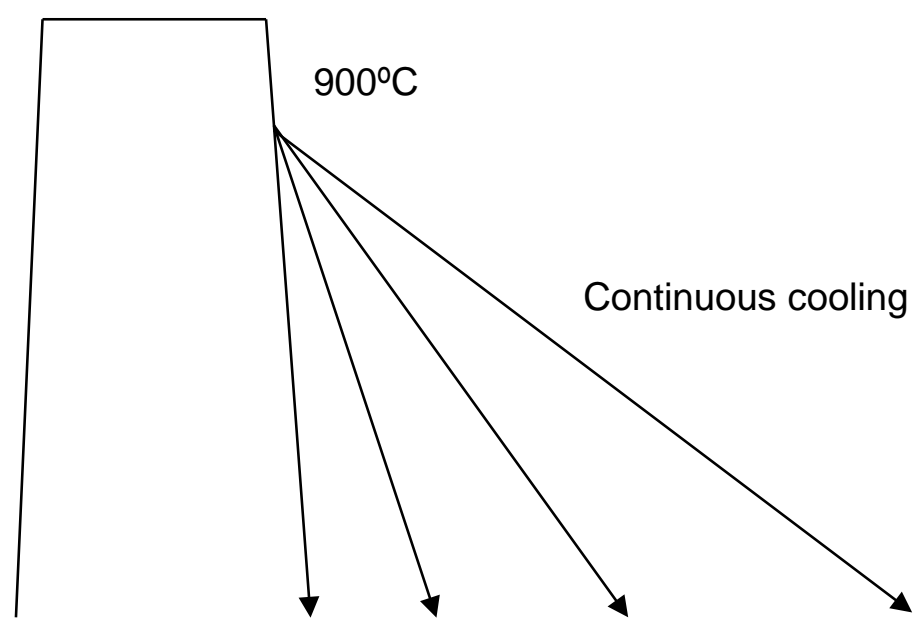

(b)

Figure 1: Temperature profiles for (a) isothermal transformation, and (b) continuous cooling.

\section{Nucleation rate}

Heterogeneous nucleation, which commonly occurs in phase transformations of steels, happens at high energy sites e.g. defects, interface, or impurities. In the case of low carbon steels, prior austenite grain boundaries are favoured sites for the heterogeneous nucleation of proeutectoid ferrite. For ferrite nucleation from austenite, the reduction in austenite grain boundary interfacial energy depends on the nucleation sites, i.e. grain faces, grain edges, and grain corners [7, 23]. Nucleation at 
each type of site results in a different interfacial energy change, and thus the probability of nucleation is also varied. However, the number densities of the grain boundary sites are also different. Therefore, the nucleation rate at each grain boundary site should be calculated separately. The allotriomorphic ferrite grain boundary nucleation rate per unit area is [7-9]:

$$
I_{b}^{j}=\frac{k_{B} T}{h} n_{s}^{j} \exp \left(-\frac{\left(K_{2}^{j} G^{*}+Q\right)}{k_{B} T}\right)
$$

Equation 1

where $\mathrm{j}$ denotes grain faces, grain edges or grain corners ( $\mathrm{f}, \mathrm{e}, \mathrm{or} \mathrm{c}), n_{s}^{j}$ is a site factor about the density of active nucleation sites per unit area of grain boundary, $Q$ is the activation energy for self-diffusion of iron, with a typical value of $240 \mathrm{~kJ} / \mathrm{mol}, \mathrm{G}^{*}$ is the critical energy for nucleation, $k_{B}$ is the Boltzmann constant, $h$ is the Planck constant, $K_{2}^{j}$ is a shape factor related to the austenite/ferrite interfacial energy per unit area, and $\mathrm{T}$ is the absolute temperature. The site factor $n_{s}^{j}$ can be described as $[7,24]$ :

$$
\begin{gathered}
n_{s}^{f}=\frac{K_{1}}{2 \delta^{2}} \\
n_{s}^{e}=\frac{K_{1}}{2 \delta d_{\gamma}} \\
n_{s}^{c}=\frac{K_{1}}{2 d_{\gamma}^{2}}
\end{gathered}
$$

Equation 2(a)

Equation 2(b)

Equation 2(c)

where $\delta$ is atomic spacing, taken as $0.25 \mathrm{~nm}, d_{\gamma}$ is the average prior austenite grain size, and $K_{1}$ is a factor to describe the fraction of the active nucleation sites. There are a large number of potential nucleation sites on the grain boundary but only a small fraction of them will actually be activated. In this work, $K_{1}$ is chosen as $1.0 \times 10^{-9}, K_{2}^{f}$ is $0.1, K_{2}^{e}$ is 0.01 , and $K_{2}^{c}$ is 0.001 , in order to fit with experimental results but they are comparable with other published literature values $[7,8]$. The overall nucleation rate is:

$$
I_{b}=I_{b}^{f}+I_{b}^{e}+I_{b}^{c}
$$

Equation 3

If the strain energy caused by nucleation is ignored, the critical energy for nucleation can be expressed as [7,8,25-27]:

$$
G^{*}=\frac{\sigma_{\gamma \alpha}^{3}}{\Delta G_{V}^{2}}
$$

Equation 4 
where $\Delta G_{V}$ is the free energy change per unit volume for ferrite nucleation from supersaturated austenite, and $\sigma_{\gamma \alpha}$ is the austenite/ferrite nucleus interfacial energy per unit area, which is assumed not to vary with interfacial orientation or alloy chemistry.

Many experimental results reported that dissolved $\mathrm{Nb}$ atoms have a retardation effect on transformation start point [1-4,27]. The presence of dissolved $\mathrm{Nb}$ atoms can decrease the nucleation rate. If all $\mathrm{Nb}$ atoms are in solid solution at the beginning of the phase transformation, they are likely to be present at higher concentrations at prior austenite grain boundaries, as schematically shown in Figure 2 (a). From the classic solute drag theory $[17,18]$, there is a solute-boundary interaction energy $E_{0}^{\prime}$ if many dissolved atoms are segregated at a boundary, as shown in Figure 2 (b). It is reasonable to assume the solute-boundary interaction energy increases the critical energy for ferrite nucleation $[2,27,28]$. As a result, the ferrite nucleation rate is decreased due to the presence of dissolved $\mathrm{Nb}$ atoms. The effect of dissolved $\mathrm{Nb}$ atoms on the nucleation rate can be expressed by adding a ' $\mathrm{Nb}$ factor', $E_{N b}$, to the classic nucleation rate equation which is shown in Equation 1, and thus the modified nucleation rate used in this research can be expressed in the following equation:

$$
I_{b}^{j}=\frac{k_{B} T}{h} n_{s}^{j} \exp \left[-\frac{\left(K_{2}^{j}\left[G^{*}+E_{N b}\right]+Q\right)}{k_{B} T}\right]
$$

Equation 5

where $E_{N b}$ is the $\mathrm{Nb}$ factor which influences the critical energy for ferrite nucleation. From classic solute drag theory $[17,18]$, the solute-boundary interaction energy $E_{0}^{\prime} \sim k_{B} T$, therefore, the $\mathrm{Nb}$ effect on the critical energy for ferrite nucleation is proposed in this work as:

$$
E_{N b}=\frac{\alpha k_{B} T}{K_{2}^{j}} C_{N b}
$$

Equation 6

where $\mathrm{C}_{\mathrm{Nb}}$ is the $\mathrm{Nb}$ content in weight percent, and $\alpha=-75$ is a constant fitted with experimental results.

If the effect of $\mathrm{Nb}$ on the nucleation rate is not considered, the calculated nucleation rates using Equation 1 for steels 1-3 during isothermal holding at $750^{\circ} \mathrm{C}$ are shown in Figure 3 (a). It can be seen that steel 3 with a higher $\mathrm{Nb}$ content even has the slightly faster nucleation rate than steels 1 and 2, because $\mathrm{Nb}$ also has an effect on 
thermodynamic properties of steels. The nucleation rate decreases with time because the free energy for the transformation $\Delta G_{V}$ becomes less with the formation of ferrite. However, if the effect of $\mathrm{Nb}$ on nucleation rate is incorporated, i.e. Equations 5 and 6 are applied, the modified nucleation rates for steels 1-3 can be calculated and have been plotted in Figure 3 (b). Steel 3 with a high Nb content has a much slower nucleation rate than steels 1 and 2 . The modified nucleation rates at the beginning of an isothermal transformation as a function of temperature between $675^{\circ} \mathrm{C}$ and $750^{\circ} \mathrm{C}$ for steels $1-3$ have been calculated and plotted in Figure 4 (a). Steel 3 with a higher $\mathrm{Nb}$ content always has the lowest nucleation rate, and steel 1 always has the highest nucleation rate. After incorporation of the $\mathrm{Nb}$ effect, the critical energy for nucleation has been changed to $\left(G^{*}+E_{N b}\right)$, and the corresponding curves of the modified critical energy for nucleation at the beginning of an isothermal transformation as a function of temperature for steels 1-3 are plotted in Figure 4 (b). The presence of dissolved $\mathrm{Nb}$ atoms increases the critical energy for nucleation, and thus steel 3 , containing $0.028 \mathrm{wt}$. \% $\mathrm{Nb}$, requires a greater driving force for ferrite nucleation than steels 1 and 2 .

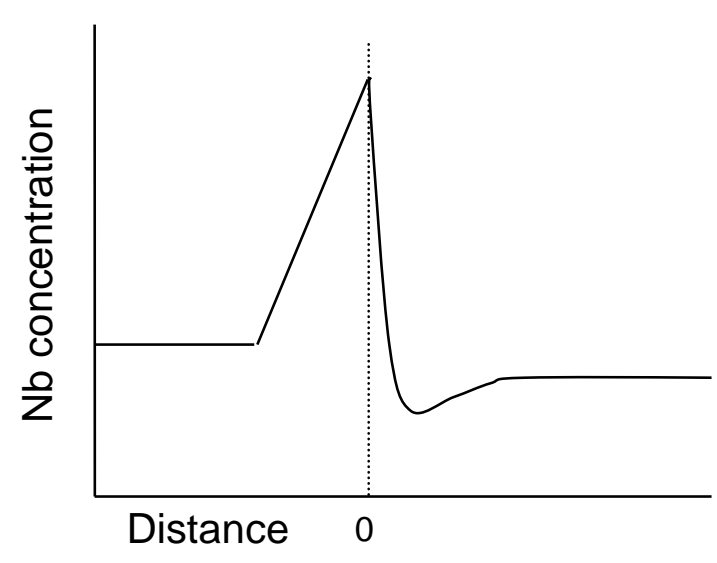

(a)

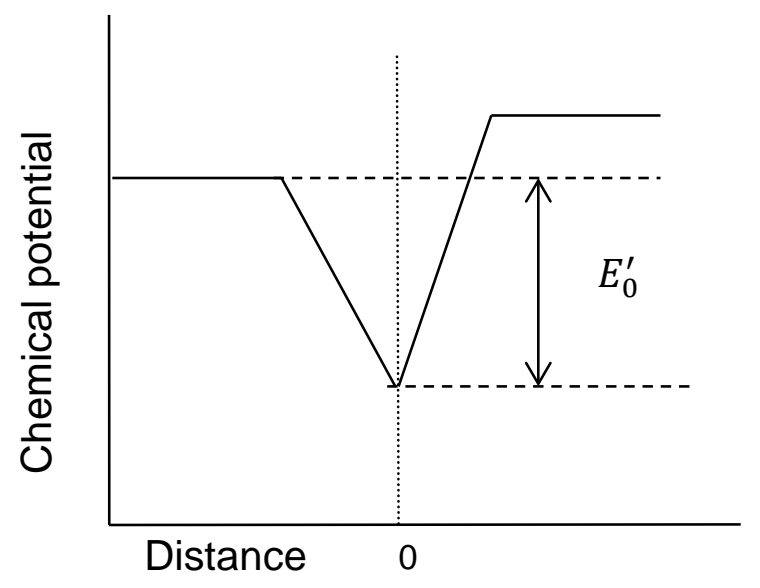

(b)

Figure 2: Schematic diagrams of (a) Nb concentration profile across an interface, and (b) chemical potential profile across the interface. 


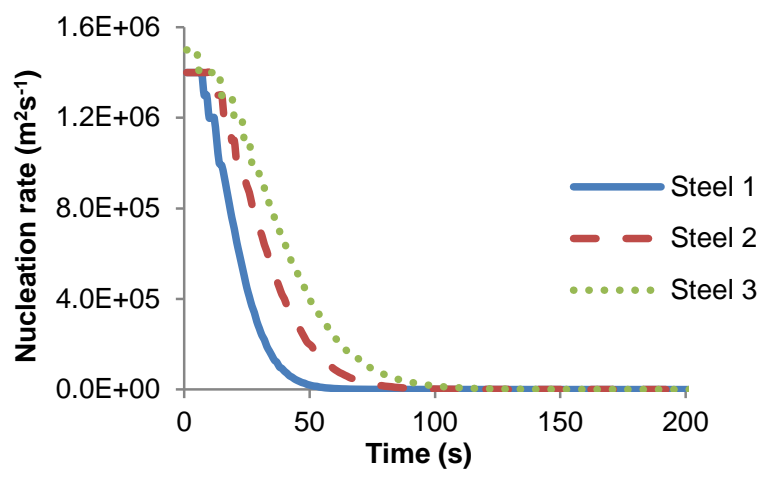

(a)

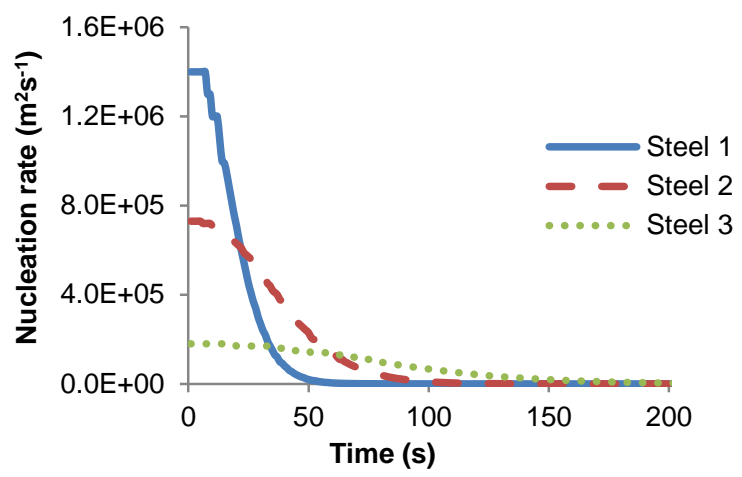

(b)

Figure 3: Calculated ferrite nucleation rate as a function of holding time at $750^{\circ} \mathrm{C}$ for steels 1-3 (a) using the pre-existing model developed by Parker without the incorporation of the $\mathrm{Nb}$ factor, and (b) using the new model with the effect of $\mathrm{Nb}$ being taken into account (Equations 5 and 6).

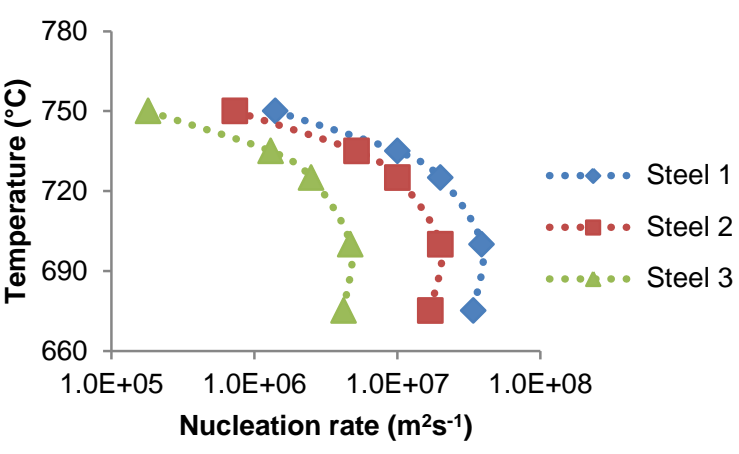

(a)

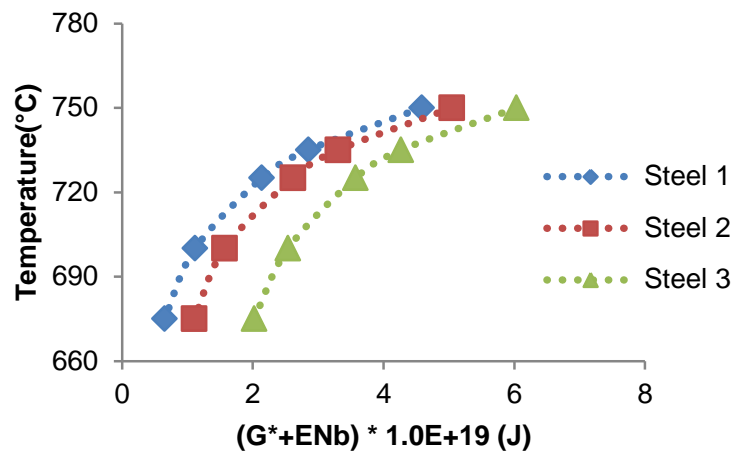

(b)

Figure 4: (a) Calculated ferrite nucleation rate, and (b) calculated critical energy for ferrite nucleation, as a function of temperature for steels 1-3 at the beginning of an isothermal transformation using the new model with the effect of $\mathrm{Nb}$ being taken into account (Equations 5 and 6).

\section{Grain growth}

For a typical transformation from austenite to allotriomorphic ferrite, carbon is partitioned ahead of the transformation front into untransformed austenite. In the case of paraequilibrium, the ferrite growth rate can be considered to be controlled by the diffusion of carbon. The carbon diffusion profile across the transformation interface can be schematically illustrated as shown in Figure 5. According to Parker [7], the velocity of the interface movement can be expressed as [7,23]:

$$
\frac{d z}{d t}=\frac{D_{C}}{\left(x^{\gamma \alpha}-x^{\alpha \gamma}\right)} \frac{\left(x^{\gamma \alpha}-\bar{x}\right)^{2}}{2 z\left(\bar{x}-x^{\alpha \gamma}\right)}
$$


where $D_{C}$ is the carbon diffusivity in austenite, $x^{\gamma \alpha}$ is the mole fraction of carbon in austenite in equilibrium with ferrite, $x^{\alpha \gamma}$ is the mole fraction of carbon in ferrite in equilibrium with austenite, $\bar{x}$ is the mole fraction of carbon in the bulk austenite, $\mathrm{z}$ is distance moved by the interface, and $\frac{d z}{d t}$ is the moving rate of the interface. It is well known that allotriomorphic ferrite has a parabolic growth rate, and the growth rate is slowed down with increasing transformation time, because the distance for carbon atoms diffusion becomes longer. The parabolic growth of ferrite grains can be mathematically expressed as [23]:

$$
z=\alpha_{1} t^{\frac{1}{2}}
$$

Equation 8

where $\alpha_{1}$ is the one-dimensional parabolic rate constant, and thus $\alpha_{1}$ can be calculated from [7]:

$$
\alpha_{1}=\left[\frac{D_{C}\left(x^{\gamma \alpha}-\bar{x}\right)^{2}}{2\left(x^{\gamma \alpha}-x^{\alpha \gamma}\right)\left(\bar{x}-x^{\alpha \gamma}\right)}\right]^{\frac{1}{2}}
$$

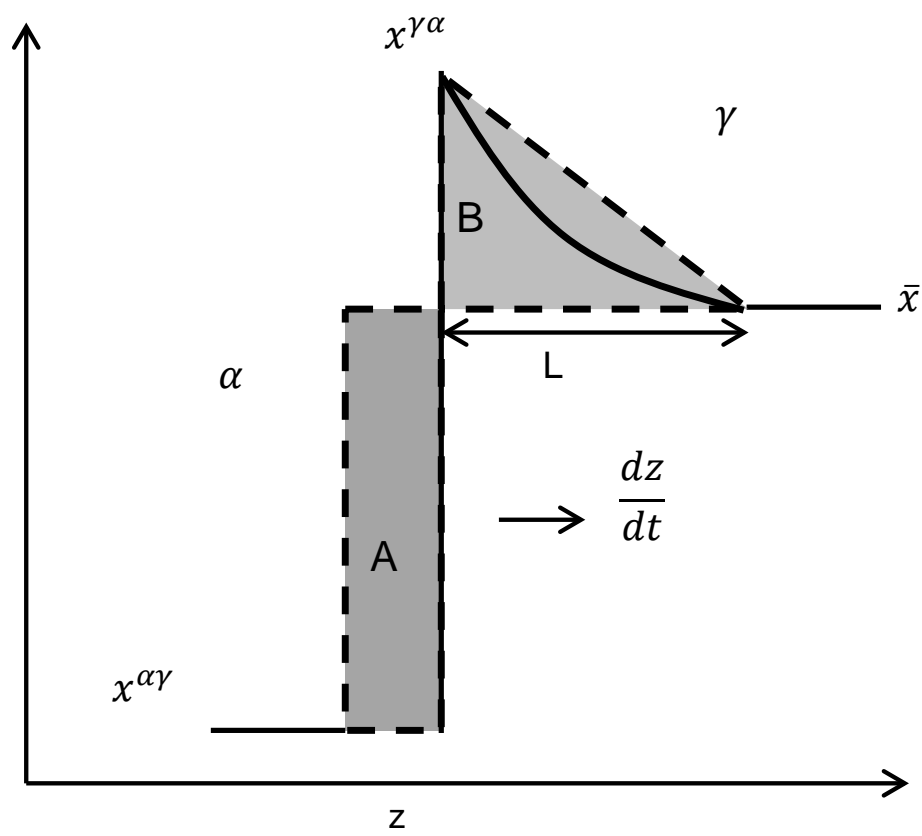

Figure 5: Schematic diagram illustrating the carbon diffusion profile across a moving austenite/ferrite interface with a rate of $\frac{d z}{d t}$. Carbon atoms partition from the shaded area $A$ to the shaded area $B$ [7].

Dissolved $\mathrm{Nb}$ atoms can apply a solute drag effect on transformation fronts to delay interface mobility. Since the ferrite growth rate is assumed to be controlled by carbon diffusion, the solute drag effect caused by dissolved $\mathrm{Nb}$ atoms can be considered as an increment in activation energy for carbon diffusion. 


$$
D_{C}=D_{0} \times e^{\left(-\frac{Q_{C}+Q_{N b, T}}{R T}\right)}=D_{0} \times \exp \left(-\frac{Q_{C}}{R T}\right) \times f(N b, T) \quad \text { Equation } 10
$$

where $D_{0}$ is the pre-exponent factor, $Q_{C}$ is the activation energy for carbon diffusion without the effect of $\mathrm{Nb}, Q_{N b, T}$ is the extra activation energy applied by dissolved $\mathrm{Nb}$ atoms, $\mathrm{R}$ is the gas constant, and $\mathrm{T}$ is the temperature $(\mathrm{K})$. In this equation, the $\mathrm{Nb}$ solute drag factor can be expressed as

$$
f(N b, T)=\exp \left[-C_{N b}^{n} \frac{\left(\mathrm{a}_{3} \mathrm{~T}^{3}+\mathrm{a}_{2} \mathrm{~T}^{2}+\mathrm{a}_{1} \mathrm{~T}\right)}{\mathrm{RT}}\right]
$$

Equation 11

where $a_{1}, a_{2}, a_{3}$, and $n$ are all fitting constants, and $C_{N b}$ is the $\mathrm{Nb}$ content in weight percent. All the constants have been determined by fitting to the isothermal transformation kinetics derived from dilatometer results at $750^{\circ} \mathrm{C}, 725^{\circ} \mathrm{C}, 700^{\circ} \mathrm{C}$ and $675^{\circ} \mathrm{C}$ for steels 2 and 3 [4] as shown in Table 2. Calculated values of the Nb solute drag factor as a function of temperature for steels 2 and 3 are plotted in Figure 6 . It can be seen that it is a $C$ shape curve like typical TTT curves, and steel 3 with a higher $\mathrm{Nb}$ content always has a lower value than steel 2. A lower value of the $\mathrm{Nb}$ solute drag factor indicates a stronger delay effect on grain growth (Equation 11). From Figure 6, the solute drag factor firstly becomes stronger with decreasing temperature towards the nose of the curve, but it then becomes weaker with a further decrease in temperature. This is because the solute drag effect varies with interface mobility, and the phase transformation mechanism has a trend to transfer from reconstructive mode to displacive mode with decreasing temperature.

The overall transformation kinetics can be calculated using the classic JohnsonMehl-Avrami-Kolmogorov (JMAK) theory [20-22]. For a parabolic growth of discshaped ferrite particles, the extent of transformation can then be calculated by [7-9]:

$$
\begin{array}{cr}
\varepsilon_{\alpha}=1-\exp \left\{-S_{v} \alpha_{1} t^{\frac{1}{2}} \int_{0}^{1}\left\{1-\exp \left[-\frac{\pi}{2} I_{b} \eta_{\alpha}^{2} \alpha_{1}^{2} t^{2}\left(1-\phi^{4}\right)\right]\right\} d \phi\right\} & \text { Equation } 12 \\
\phi=\frac{y}{\alpha_{1} t^{\frac{1}{2}}} & \text { Equation } 13
\end{array}
$$

where $\mathrm{y}$ is the distance between the interaction area of a particle with a parallel plane to the austenite grain boundary, $S_{v}$ is the grain boundary surface area per unit 
volume, calculated as $2 / d_{\gamma}$, and $\eta_{\alpha}$ is the aspect ratio (radius to thickness) of a particle, taken as 3 for a disc of ferrite nucleated on an austenite grain boundary $[7,8]$.

Table 2: Values of the fitting factors for the Nb solute drag factor

\begin{tabular}{ccccc}
\hline Fitting factor & $\mathrm{a}_{1}$ & $\mathrm{a}_{2}$ & $\mathrm{a}_{3}$ & $\mathrm{n}$ \\
\hline Value & $-1.39 \star 10^{4}$ & 28.4 & -0.014 & 0.5 \\
\hline
\end{tabular}

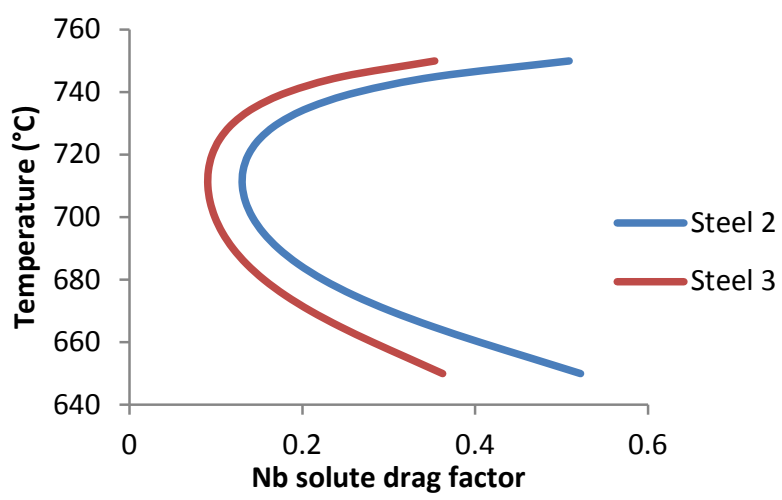

Figure 6: The relationship between $f(\mathrm{Nb}, \mathrm{T})$ and temperatures for steels 2 and 3 in the new model which contains the modified factor for the influence of $\mathrm{Nb}$ taking into account temperature and $\mathrm{Nb}$ concentration.

\section{Validation of the model}

The new model was used to predict isothermal transformation kinetics at $750^{\circ} \mathrm{C}$ and $700^{\circ} \mathrm{C}$ for steels $1-4$, as shown in Figure 7 (a) and (b). Very good agreement between the model and experimental data was obtained. Although the new model was proposed based on the isothermal transformation kinetics for steels 2 and 3, it also successfully predicted the isothermal transformation kinetics for steel 4 with a higher $\mathrm{Nb}$ content. In addition, the new model predictions, the predictions from the original model without the $\mathrm{Nb}$ effects, and the experimental results for continuous cooling kinetics for steels 1 and 3 at different cooling rates are compared in Figure 8. For the $\mathrm{Nb}$ free steel 1 , both the new model predictions and the original model predictions have good consistency with the experimental results. For the $\mathrm{Nb}$ containing steel 3 , the new model predictions have much better accuracy than the original model, especially for the $50 \%$ transformation temperature. These successful predictions on the continuous cooling transformation data, which were not used to tune the model, validate and indicate the accuracy of the new model. 


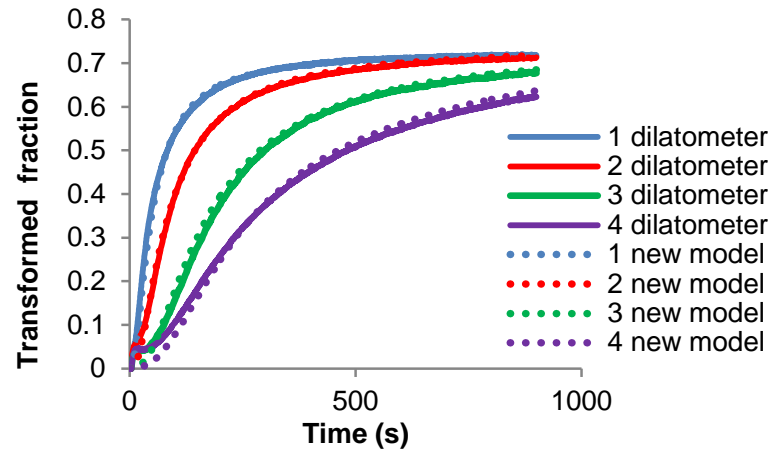

(a)

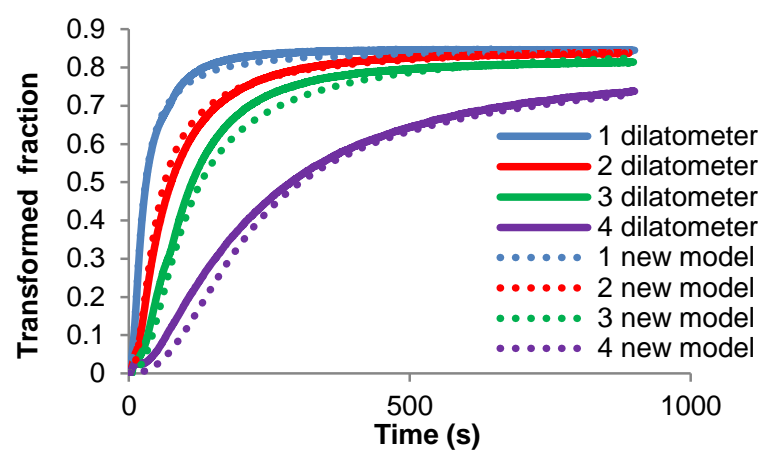

(b)

Figure 7: Comparisons between new model predictions and experimental data for steels $1,2,3$ and 4 isothermal transformations at (a) $750^{\circ} \mathrm{C}$, and (b) $700^{\circ} \mathrm{C}$.

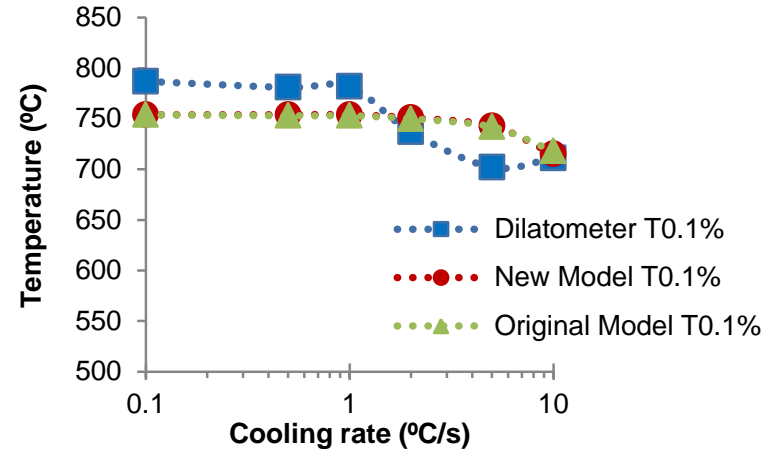

(a)

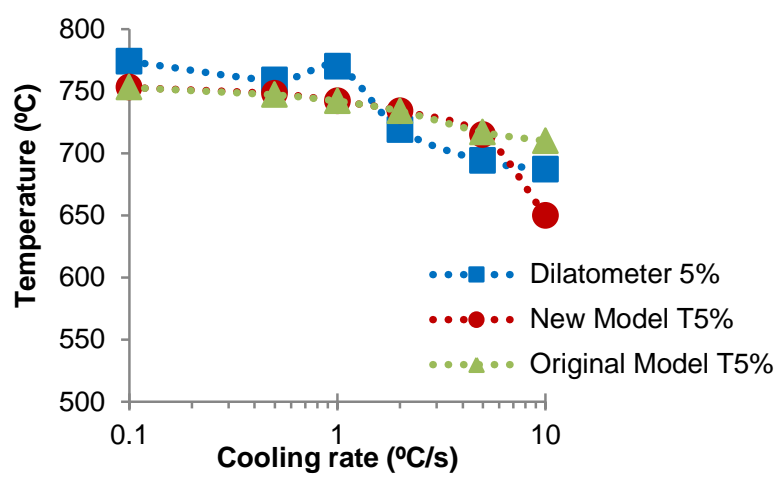

(c)

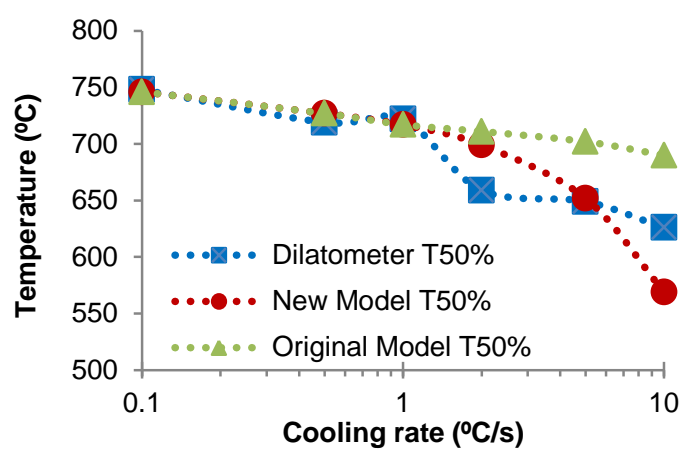

(e)

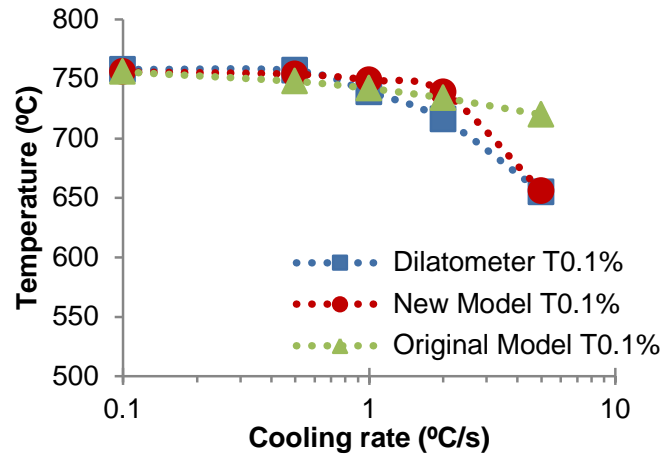

(b)

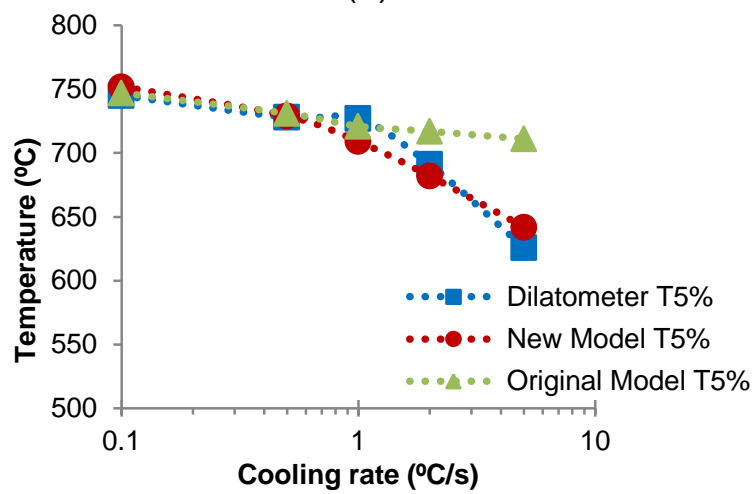

(d)

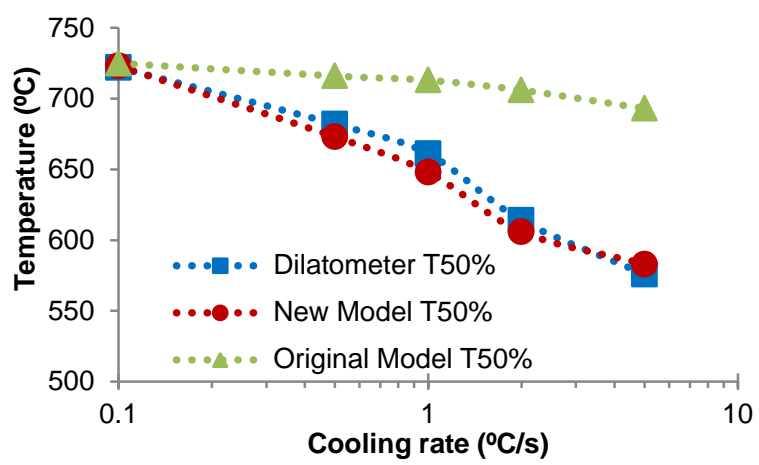

(f)

Figure 8: Comparisons of transformation kinetics during continuous cooling between experimental results from the dilatometer and the modelling predictions: (a) T0.1\% for steel 1, (b) T0.1\% for steel 3, (c) T5\% for steel 1, (d) T5\% for steel 3, (e) T50\% for steel 1 , and (f) T50\% for steel 3. 
In order to further prove the accuracy of the new model, it was also used to predict the isothermal transformation start times for some other steels with $\mathrm{Nb}$ contents of 0 wt. \%, 0.011 wt. \%, and 0.05 wt. \%, respectively. The transformation start points of these steels have been experimentally determined by Tata Steel using dilatometry a few years ago [29], and they are compared with the new model predictions, as shown in Figure 9. It can be found that the predicted TTT diagrams using the new model are generally consistent with the trend of the experimental results. From all these comparisons, the new model has been validated and shown to be an accurate model to predict the transformation kinetics for these types of low alloy $\mathrm{Nb}$ containing steels, and the modification of the nucleation rate and the grain growth rate calculations appears to be successful.

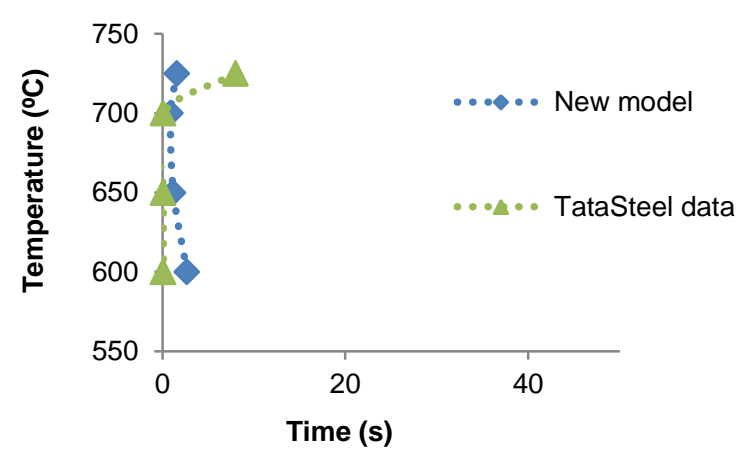

(a)

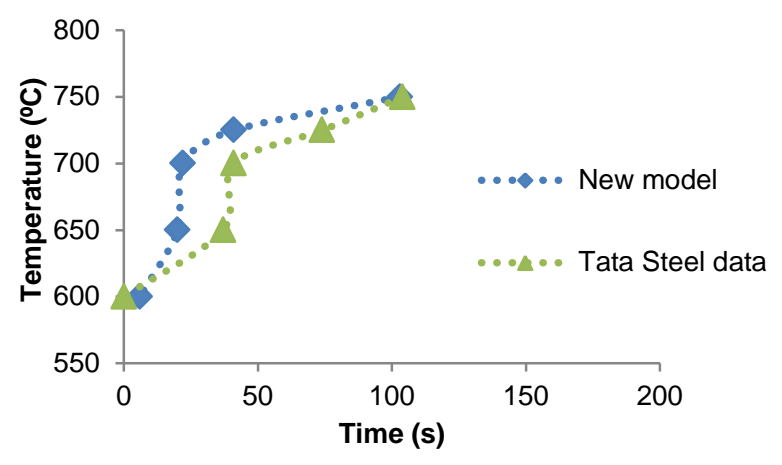

(c)

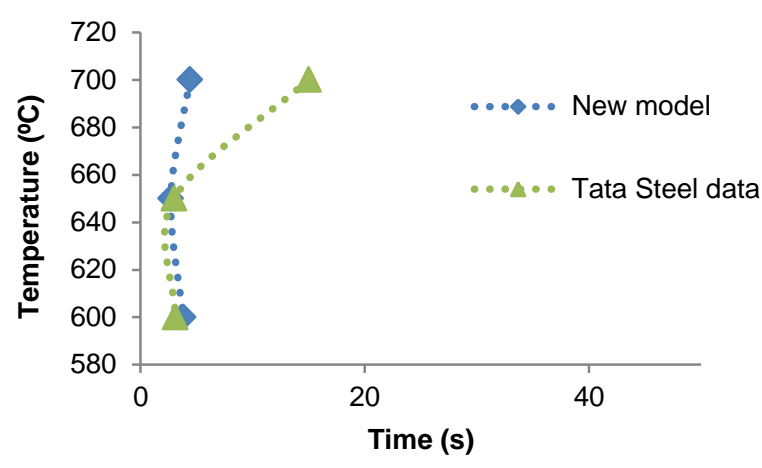

(b)

Figure 9: TTT diagrams of the new model predictions and Tata Steel previous results [29] for (a) a Nb free steel, (b) a steel with $0.011 \mathrm{wt} \% \mathrm{Nb}$, and (c) a steel with $0.05 \mathrm{wt}$ \% $\mathrm{Nb}$. 


\section{Conclusions}

This paper presents the incorporation of the effects of $\mathrm{Nb}$ into a phase transformation model together with the validation of the new model. It is well known that the presence of $\mathrm{Nb}$ causes a retardation effect on transformation kinetics. The effects of $\mathrm{Nb}$ on transformation kinetics can be attributed to the effect on nucleation rate and the effect on grain growth rate. Segregation of dissolved $\mathrm{Nb}$ atoms at prior austenite grain boundaries increases the critical energy for ferrite nucleation, and thus the nucleation rate is reduced. The solute drag effect of $\mathrm{Nb}$ on the ferrite grain growth rate can be considered as an increment in the activation energy for carbon diffusion. After incorporation of the $\mathrm{Nb}$ effects, the new model predictions were quite consistent with experimental results for different $\mathrm{Nb}$ containing steels isothermally transformed at various temperatures, and also continuously cooled at different cooling rates. Therefore, the new model is proved to be successful for transformation kinetics prediction for $\mathrm{Nb}$ containing steels.

\section{Acknowledgement}

The authors gratefully thank Tata Steel UK Limited and Loughborough University for funding this work.

\section{References}

[1] A.J. DeArdo, Proceedings of the International Symposium Niobium 2001, Orlando, TMS, 2001, pp. 427-500.

[2] C. Fossaert, G.I. Rees, T.Maurickx, and H.K.D.H.Bhadeshia, Metall. Mater. Trans. A, 1995, vol. 26, pp. 21-30.

[3] G. I. Rees, J. Perdrix, T. Maurickx, and H. K. D. H. Bhadeshia, Mater. Sci. Eng. A, 1995, vol. 194, pp. 179-186.

[4] L. Wang, S.V. Parker, A.J. Rose, G.D. West, and R.C. Thomson, J. Iron Steel. Res. Int., 2011, vol. 18 (1-1), pp. 208-212.

[5] F. Fazeli, and M. Militzer; J. Iron Steel. Res. Int., 2011, vol. 18 (1-2), pp. 658663.

[6] K.J. Lee, and J.K. Lee, Scripta Mater., 1999, vol. 40 (7), pp. 831-836.

[7] S.V. Parker, Modelling of Phase Transformations in Hot-Rolled Steels, PhD Thesis, University of Cambridge, 1997. 
[8] R.C. Reed, and H.K.D.H. Bhadeshia, Mater. Sci. Tech., 1992, Vol. 8, pp. 421435.

[9] J.W. Cahn, Acta Metall., 1956, Vol. 4, pp. 449-459.

[10] H.K.D.H. Bhadeshia, Metal Sci., 1982, vol. 16, pp. 159-165.

[11] M. Gómez, S.F. Medina and G. Caruana: ISIJ Int., 2003, Vol. 43, pp. 12281237.

[12] M.G. Mecozzi, J. Sietsma and S. van der Zwaag: Acta Mater., 2006, Vol. 54, pp. 1431-1440.

[13] Y. Takahama and J. Sietsma, ISIJ Int., 2008, Vol. 48, pp. 512-517.

[14] T. Jia and M. Militzer: Metall. Mater. Trans. A, 2015, Vol. 46A, pp. 614-621.

[15] J.W. Cahn, Acta Metall., 1962, vol. 10 (9), pp. 789-798.

[16] M. Hillert, and B. Sundman, Acta Metall., 1976, vol. 24 (8), pp. 731-743.

[17] G.R. Purdy, and Y.J.M. Brechet, Acta Metall. Mater., 1995,vol. 43 (10),pp. 3763-3774.

[18] F. Fazeli, and M. Militzer, Metall. Mater. Trans. A, 2005, vol. 36 (6), pp. 13951405.

[19] M. Enomoto, Acta Mater., 1999, vol. 47 (13), pp. 3533-3540.

[20] M. Avrami, Journal of Chemical Physics, 1939, vol. 7 (12), pp. 1103-1112.

[21] M. Avrami, Journal of Chemical Physics, 1940, vol. 8 (2), pp. 212-224.

[22] M. Avrami, Journal of Chemical Physics, 1941, vol. 9 (2), pp. 177-184.

[23] I. Tamura, T. Iron Steel I. Jpn, 1987, vol. 27 (10), pp. 769-779.

[24] J.W. Christian, The Theory of Phase Transformation in Metals and Alloys, Part 1, $2^{\text {nd }}$ edition, Pergamon, Oxford, 1965.

[25] W.C. Johnson, C.L. White, P.E. Marth, P.K. Ruf, S.M. Tuominen, K.D. Wade, K.C. Russell, and H.I. Aaronson, Metall. Trans. A, 1975, vol. 6 (4), pp. 911919.

[26] W.F. Lange, M. Enomoto, and H.I. Aaronson, Metall. Trans. A, 1988, vol. 19 (3),pp. 427-440.

[27] P. Yan and H.K.D.H. Bhadeshia, Mater. Sci. Tech., 2015. Vol. 31, pp. 10661076.

[28] T. Furuhara, T. Yamaguchi, G. Miyamoto, and T. Maki, Mater. Sci. Technol., 2010, vol. 26, pp. 392-397.

[29] S.V. Parker, private communication, 2012. 